\title{
A Numerical Study of Effects of Valley-Weathering and Valley-Shape-Ratio on the Ground Motion Characteristics
}

\author{
Jay P. NARAYAN, Muhammad Y. ARAFAT, \\ and KAMAL \\ Department of Earthquake Engineering, Indian Institute of Technology Roorkee, \\ Roorkee, India; e-mail: jaypnfeq@iitr.ernet.in
}

\begin{abstract}
A study of combined effects of valley-weathering and valley-shaperatio on the ground motion characteristics and associated differential ground motion (DGM) is documented in this paper. In order to properly quantify the weathering effects, a forth-order-accurate staggered-grid viscoelastic time-domain finite-difference program has been used for the simulation of $\mathrm{SH}$-wave responses. Simulated results revealed that the defocusing caused by valley is frequency-independent in contrast to the ridge-focusing. A decrease of average spectral amplification (ASA) with an increase of shape-ratio of the non-weathered triangular and elliptical valleys was obtained. Overall, the amplification and de-amplification pattern was larger in case of triangular valleys as compared to the elliptical valleys. It can be concluded that the dwelling within or near the topcorners of weathered valleys may suffer more damage as compared to their surroundings. A weathered triangular valley with large shape-ratio may cause unexpected damage very near its top-corners since both the ASA and DGM are largest.
\end{abstract}

Key words: viscoelastic time-domain response of valleys, finitedifference method, weathering and valley-shape-ratio effects, local site effects.

Ownership: Institute of Geophysics, Polish Academy of Sciences;

(C) 2015 Narayan et al. This is an open access article distributed under the Creative Commons Attribution-NonCommercial-NoDerivs license,

http://creativecommons.org/licenses/by-nc-nd/3.0/. 


\section{INTRODUCTION}

This research work is stimulated with the changing structural scenario in the hilly areas. There is day by day increase of dwelling as well as the number of mega structures such as dams, bridges, and other life-lines across the valleys in the hilly areas. These mega structures may be subjected to non-uniform ground motions due to the spatial variability in ground motion caused by the valley topography. The earthquake records, post earthquake damage surveys, and simulations have revealed a ground motion amplification at the ridge top and de-amplification at the trough of a valley (Geli et al. 1988, Kawase and Aki 1990, Pedersen et al. 1994, Spudich et al. 1996, Narayan and Rai 2001, Narayan and Prasad Rao 2003, Narayan 2003, Kamalian et al. 2006). However, relatively less attention is given to the valley effects on the ground motion characteristics, may be due to the de-amplification of ground motion in the valleys. But theoretical studies have revealed that a valley may cause large ground motion amplification near its edges (Sextos et al. 2003, Zhou et al. 2010, Gao et al. 2012). The de-amplification and amplification patterns across a valley along with the geometry of the valley itself may cause intense differential ground motion (DGM). The DGM developed along the synclinal part of the valley may adversely affect the structures situated in valleys since it induces significant additional stresses in the structures as compared to the ones induced if the motions at the supports were considered to be identical. The extended structures across the valleys like dams, bridges, and other lifelines are largely affected by the DGM caused by the valley topography. So, the rapid development of long-span structures in the hilly areas calls for the quantification of amplification and de-amplification and DGM across the valley for the cost effective earthquake engineering.

In the past, seismic responses of homogeneous valleys of various shapes and size (triangular, U-shaped, trapezoidal, semi-sine, semi-circular, semielliptical, semi-cylindrical, etc.) have been simulated for the incident $S H, S V$, and $P$ waves using different methods like Aki-Larner method, finitedifference (FD) method, finite-element methods, boundary element methods, and hybrid methods (Trifunac 1972, Wong 1982, Bouchon 1985, Hirai 1988, Sánchez-Sesma and Campillo 1991, Nguyen and Gatmiri 2007, Tsaur and Chang 2008, Gao et al. 2012). As far as we know, there are only few studies on the effects of valley-weathering on the ground motion characteristics. Zhao $(2009,2010)$ simulated the $P$ - and $S V$-wave response of a weathered $\mathrm{V}$-shaped valley for different weathering velocity and single shape-ratio using coupled method of finite and dynamic infinite-elements. Further, the weathering considered by Zhao (2010) was only along the slant part of the valley, although weathering thickness may be even larger on the horizontal/ gentle-slope part of the valley. It seems that almost no work is carried out to 
quantify the combined effects of valley-weathering and valley-shape-ratio on the ground motion amplification and DGM across the valley.

This paper presents the combined effects of valley-shape, valley-shaperatio, and the valley-weathering on the amplification of the $S H$ wave as well as the DGM along the valley-flanks in details. It is verified whether valley de-amplification is frequency dependent or frequency independent. Snapshots at different moments are also computed to infer reflections from curved part of the valley, diffractions from the top corners of the valley, and the amplification patterns. A forth order accurate $S H$-wave time-domain viscoelastic FD program developed by Narayan and Kumar (2013) was used to simulate the responses of various considered models.

\section{SALIENT ASPECTS OF THE USED FD COMPUTER PROGRAMS}

A fourth order accurate $S H$-wave FD program developed by Narayan and Kumar (2013) is used for the simulation of responses of various valley models. This computer program is based on the staggered grid FD approximation of the viscoelastic $S H$-wave equations for the heterogeneous medium with a variable grid-size. The frequency-dependent damping in the time-domain FD simulations is incorporated based on the well known Generalized Maxwell Body - Emmerich and Korn (GMB-EK) rheological model (Emmerich and Korn 1987). A material independent anelastic function developed by Kristek and Moczo (2003) was used since it is preferable in case of material discontinuities in the FD grid (Narayan and Kumar 2013, 2014). The effective value of the unrelaxed modulus of rigidity $\mu_{u}$ and the density $\rho$ at the desired motion in a grid cell is obtained using the harmonic and arithmetic means, respectively, to incorporate the material discontinuity (Moczo et al. 2002, Narayan and Kumar 2008). An improved vacuum formulation proposed by Zeng et al. (2012) is used as a free surface boundary condition. Zeng et al. (2012) reported that the improved vacuum formulation fully satisfies the free surface boundary condition by using an appropriate combination of the staggered-grid and a parameter averaging scheme proposed by Moczo et al. (2002). Both the sponge boundary condition of Israeli and Orszag (1981) and absorbing boundary condition of Clayton and Engquist (1977) were implemented on the model edges to avoid the edge reflections (Kumar and Narayan 2008).

\section{VALLEY EFFECTS}

It is well documented that the ground motion amplification caused by the ridge-focusing is frequency dependent (Geli et al. 1988). To find out whether valley-defocusing is frequency dependent, the $S H$-wave response of an elastic triangular valley (TRV) was computed using the incident horizon- 


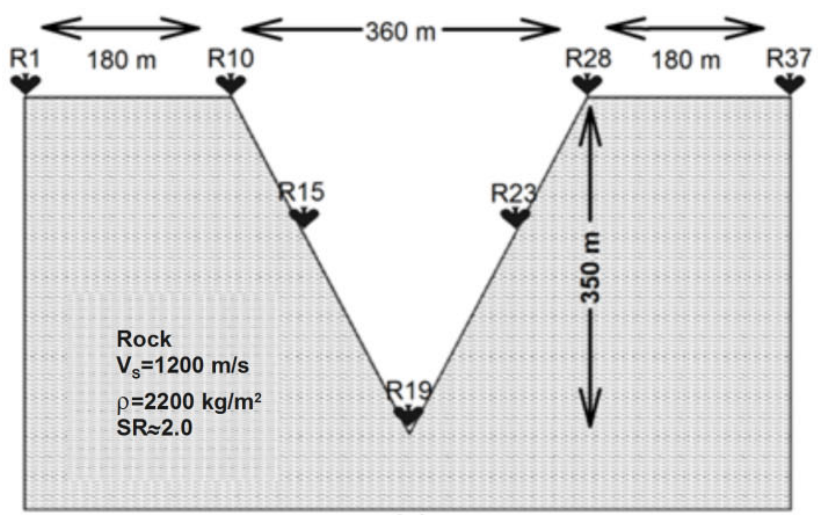

(a)

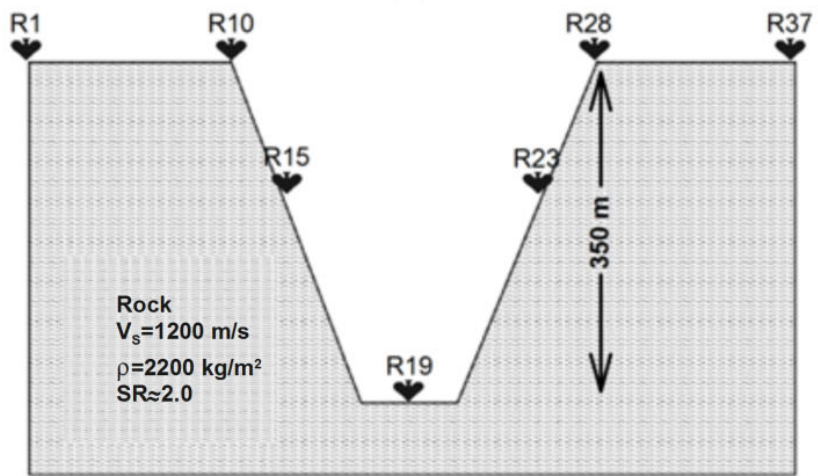

(b)

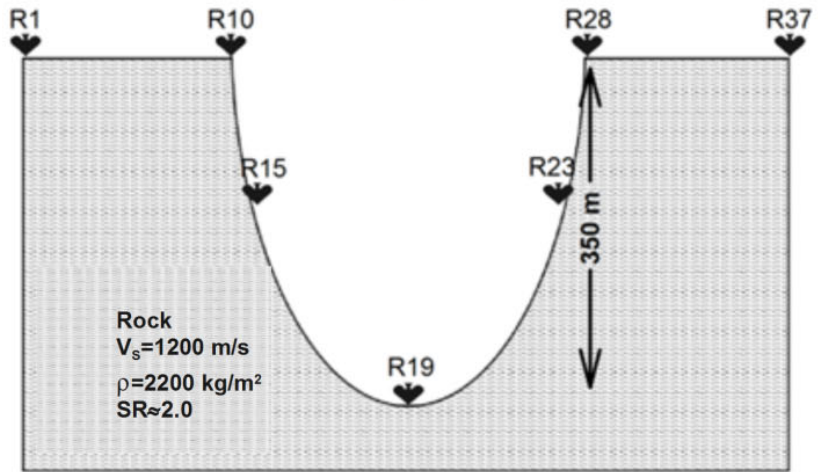

(c)

Fig. 1. Triangular (a), trapezoidal (b), and elliptical (c) valley models.

tal plane $S H$-wave front. Figure 1 a shows a cross-section of a TRV model. The $S$-wave velocity and density for elastic rock are given in Table 1 . The width and depth of the TRV model were taken as 360 and $350 \mathrm{~m}$, respec- 
Rheological parameters for the elastic and viscoelstic rock and the visoelastic weathering material

\begin{tabular}{|c|c|c|c|c|}
\hline \multirow{2}{*}{ Materials } & \multicolumn{2}{|c|}{$\begin{array}{c}\text { Velocity and quality } \\
\text { factor at } F_{R}\end{array}$} & \multirow{2}{*}{$\begin{array}{l}\text { Density } \\
{\left[\mathrm{kg} / \mathrm{m}^{3}\right]}\end{array}$} & \multirow{2}{*}{$\begin{array}{c}\text { Unrelaxed modulus } \\
\text { of rigidity } \\
\text { [GPa }]\end{array}$} \\
\hline & $\begin{array}{c}V_{S} \\
{[\mathrm{~m} / \mathrm{s}]}\end{array}$ & $\begin{array}{l}\text { Quality } \\
\text { factor }\end{array}$ & & \\
\hline Elastic rock & 1200 & - & 2200 & 3.168 \\
\hline Viscoelastic rock & 1200 & 120 & 2200 & 3.240 \\
\hline Viscoelastic weathering & 600 & 60 & 2000 & 0.733 \\
\hline
\end{tabular}

tively. A plane horizontal $S H$-wave front was generated using various point sources at a depth of $0.50 \mathrm{~km}$ with respect to the trough of the TRV model. The shear stress $\sigma_{Z Y}$ in the form of a Ricker wavelet was used to generate the point sources along a horizon. The used Ricker wavelet with $4.0 \mathrm{~Hz}$ dominant frequency has a considerable spectral amplitude in the frequency band of 0.0 to $10.0 \mathrm{~Hz}$. Time step and grid size were taken as $0.0005 \mathrm{~s}$ and $2 \mathrm{~m}$, respectively. Seismic responses along the free surface were computed at 37 equidistant $(20 \mathrm{~m}$ apart) receiver points extending from $360 \mathrm{~m}$ left to the $360 \mathrm{~m}$ right of the axis of the TRV model. Figure 2a depicts the $S H$-wave response of the elastic TRV model. The incident $S H$ wave and diffracted $S H$ wave are very clearly visible on the receiver points in the valley as well as at the free surface. Analysis of this figure shows that the $\mathrm{SH}$-wave characteristics are highly affected by the presence of the valley. On an average, a decrease of amplitude of the incident $S H$ wave towards the trough of valley can be inferred. The diffracted waves from the top corners of the valley and defocusing caused by the valley topography may be responsible for the amplitude variation along both the inclined and the horizontal flanks of the TRV model. Very large amplitude at the receivers' points very near the top-edges of valley may be due to interference of the incoming and diffracted waves. It means the response very near the top-edge of the valley cannot be used as a reference trace for the computation of topographic amplifications. In order to avoid the aforesaid problem, seismic response without considering the valley in the model was used for the computation of spectral amplification/de-amplification caused by the valley (Boore 1972, Lee et al. 2009). A comparison of the $S H$-wave response of a model without valley with the response at the tough of the elastic TRV model is shown in Fig. 2b. This figure clearly depicts the decrease of amplitude of incident $S H$ wave (first arrival) due to the valley de-focusing. The diffracted $S H$ waves from the top corners of the valley are also visible as the second arrival. 

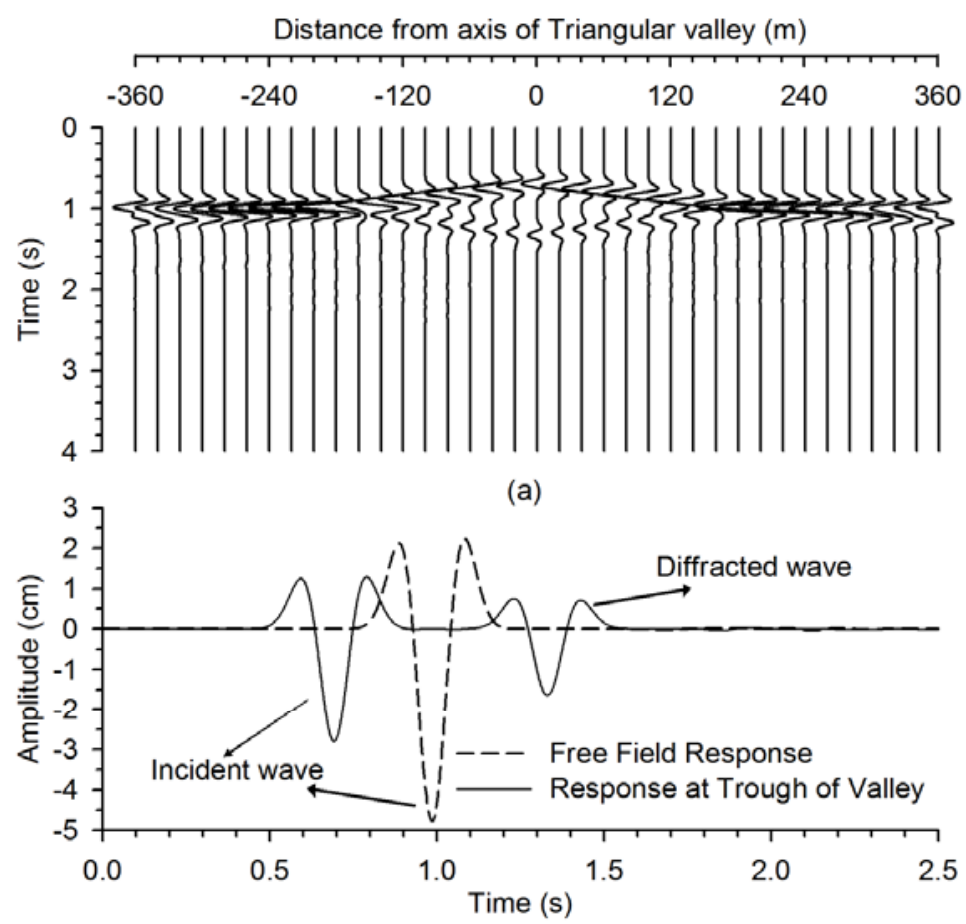

(b)

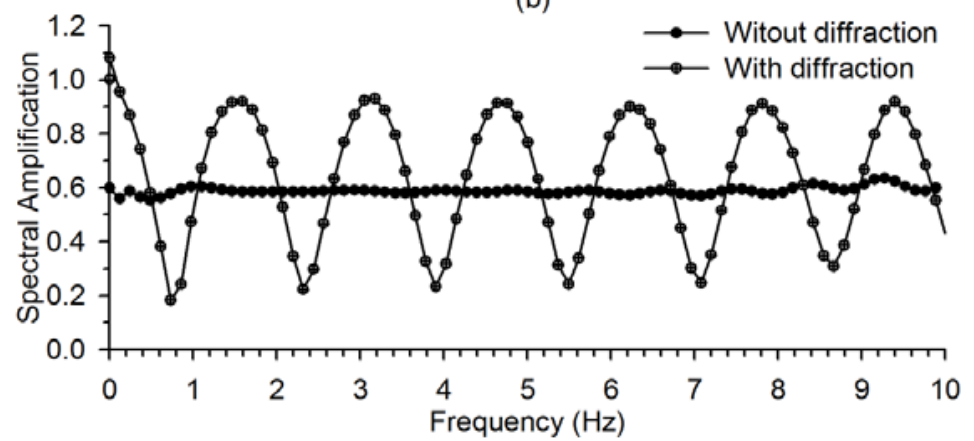

(c)

Fig. 2: (a) $\mathrm{SH}$-wave response of elastic TRV model, (b) response at the trough of valley and free field, and (c) spectral amplification with and without diffracted waves.

In order to infer whether valley de-focusing is frequency dependent or not, the spectral amplification was computed at the trough of the valley without considering the diffracted $\mathrm{SH}$ wave. Before computing the FFT of the trace recorded on the trough of valley for computation of spectral amplification, the diffracted waves were removed manually. Figure $2 \mathrm{c}$ depicts the spectral amplification at the trough of the valley with and without consider- 
ing the diffracted waves. The computed spectral amplification without considering the diffracted wave reveals that the valley de-focusing is frequencyindependent in contrast to the ridge-focusing (Geli et al. 1988). On an average, the amplification factors for all the considered frequencies are more or less equal to 0.58 at the valley-trough. The analytically computed $S H$-wave

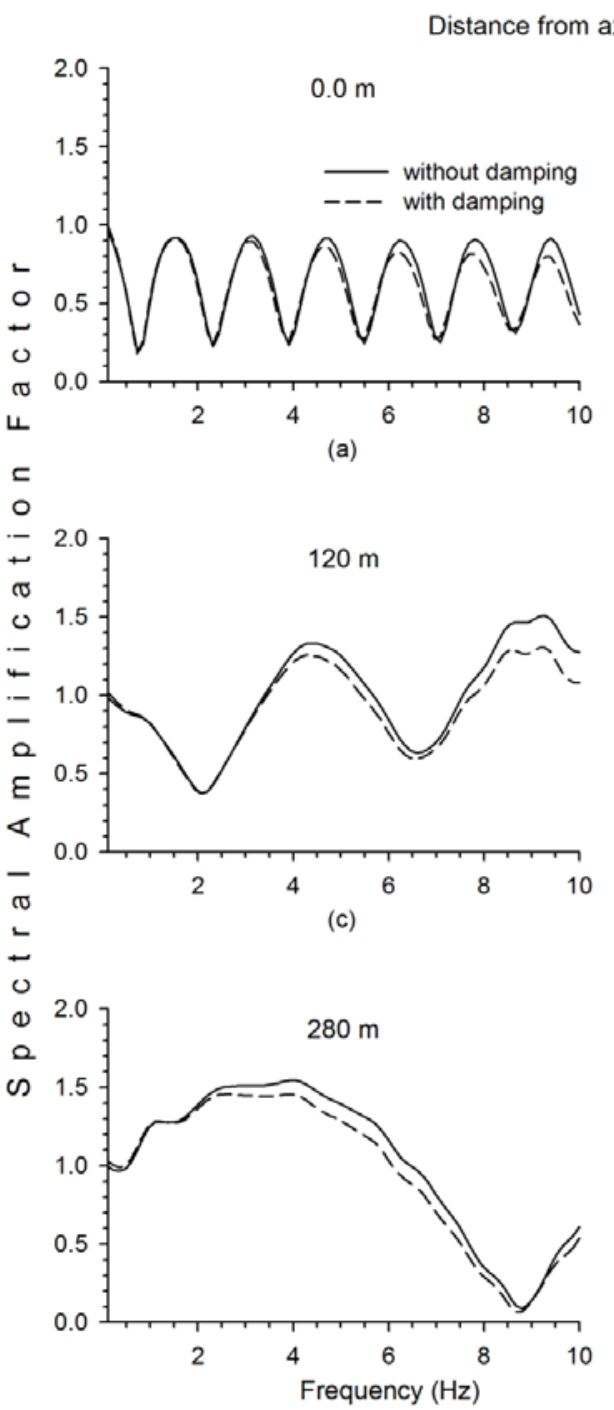

(e)

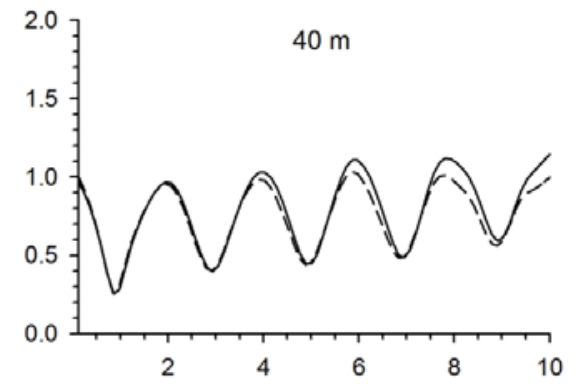

(b)

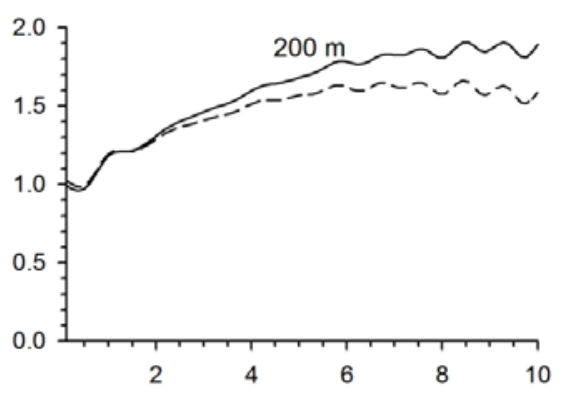

(d)

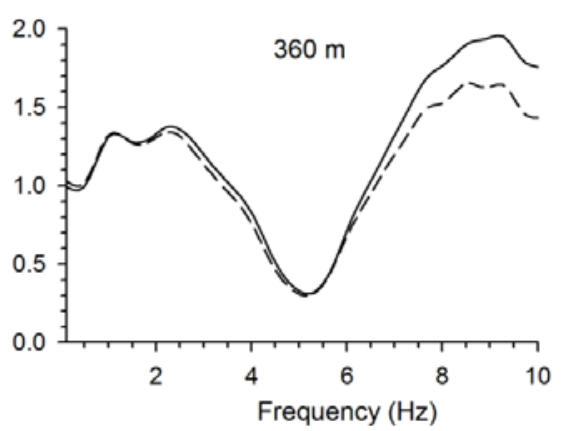

(f)

Fig. 3. A comparison of spectral amplification in case of elastic and viscoelastic responses of TRV model. 
amplification at the trough of the triangular valley is also equal to 0.58 (Faccioli 1991). An excellent match of numerically computed amplification with the analytical one also reflects the accuracy of the used modified vacuum formulation as free surface boundary condition (Zeng et al. 2012). On the other hand, the spectral amplification is highly varying with frequency if diffracted waves are considered (Fig. 2c). The frequency independent defocusing was also reported by Kumar and Narayan (2013) based on the analysis of response of an anticlinal unbounded basement topography. So, it can be concluded that the de-amplification caused by the valley-de-focusing is frequency independent in contrast to the amplification caused by the ridgefocusing (Geli et al. 1988).

In order to infer the material damping on the spectral amplification, seismic responses of the viscoelastic valley model were also computed. The phase velocity and quality factor at a reference frequency, density and unrelaxed modulus of rigidity in the viscoelastic rock are given in Table 1. A comparison of spectral amplification at different location along the crosssection of the valley in case of elastic and viscoelastic response is shown in Fig. 3. The analysis of Figs. 2c and 3 reveals that the cause of ups and downs in spectral amplification pattern is the presence of diffracted waves and its effect if decreasing with an increase of distance from the top-edges of the valley. However, it is surprising to note that the spectral amplification is consistently increasing with an increase of frequency in case of elastic response very near the top-edges of the valley (Fig. 3d). The maximum amplification in case of viscoelastic response is 1.5 at $10 \mathrm{~Hz}$.

\section{SH-WAVE SNAPSHOTS}

In order to demonstrate the behaviour of incident $S H$ wave along the flanks, bottom and top edges of the elliptical valley, snapshots were computed at different times. Snapshots were computed in a rectangular area extending $20 \mathrm{~m}$ above to $480 \mathrm{~m}$ below the free surface $540 \mathrm{~m}$ south to $540 \mathrm{~m}$ north of axis of elliptical valley. The snapshots at times 0.54 and $0.62 \mathrm{~s}$ (Fig. 4a, b) depict that the $\mathrm{SH}$-wave front has entered in the considered rectangular area and the outline of the valley is being reflected. The propagation of incident $\mathrm{SH}$ wave towards the free surface can also be inferred. Figure $4 \mathrm{c}-\mathrm{f}$ shows the splitting of the incident $S H$-wave front, the reflection from the flanks of the valley and the diffraction at the trough. Further, the reflected $S H$ waves from the flanks of the valley are not propagating towards the free surface. Figure $4 \mathrm{~g}$ clearly depicts the amplitude build-up very near the top corners of the valley. The reflected $S H$ wave from the free surface and the diffracted $S H$ wave from the top edges of elliptical valley and their propagation can be very clearly inferred from Fig. 4h-1. 

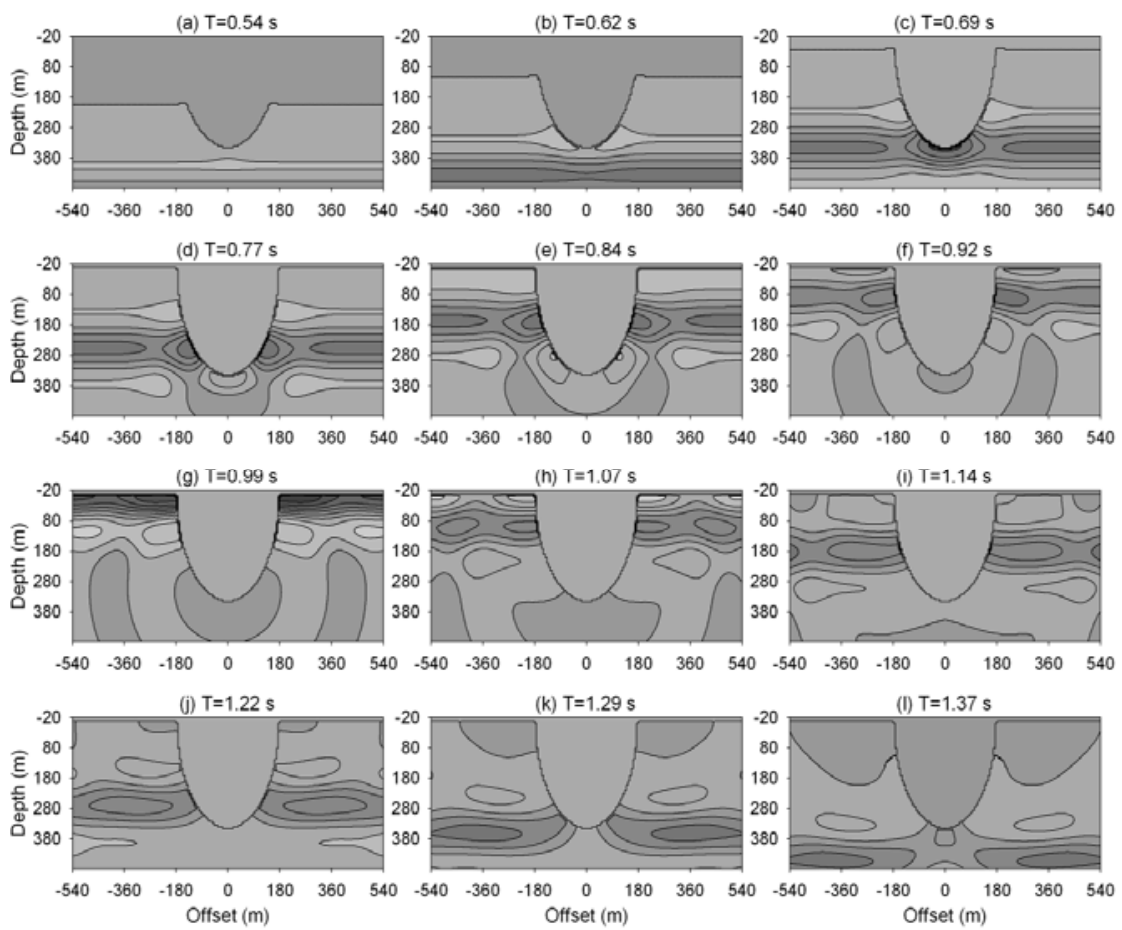

Fig. 4. SH-wave snapshots for elliptical valley at different moments (note: amplitude variation in scale is in $\mathrm{cm}$ ).

\section{EFFECTS OF VALLEY SHAPE}

To study the effects of shape of the valley on the amplification pattern, $\mathrm{SH}$ wave responses of viscoelastic triangular valley (TRV), trapezoidal valley (TPV), and an elliptical valley (ELV) models were computed. The shaperatio for the viscoelastic TRV, TPV, and ELV models was the same as given in Fig. 1. The shape-ratio is the ratio of depth of valley with the half-width of the valley-mouth. The $S$-wave velocity and quality factor at a reference frequency $(1.0 \mathrm{~Hz})$, density and unrelaxed modulus of rigidity are given in Table 1. Further, relaxation frequencies were taken as $0.02,0.2,2.0$, and $20.0 \mathrm{~Hz}$ for the computation of anelastic coefficients and anelastic functions (Narayan and Kumar 2013). The other model parameters and source receiver configuration were the same as in the previous case. Figure 5a-c shows the seismic responses of the TRV, TPV, and ELV models, respectively. Analysis of Fig. 5 reveals that both the de-focusing effect at the valley-troughs and diffractions from the top corners are greater in case of the TRV model and least in case of the ELV model. The seismic responses of the TRV and TPV models seem to be almost similar, except of the amplitude de-amplification 


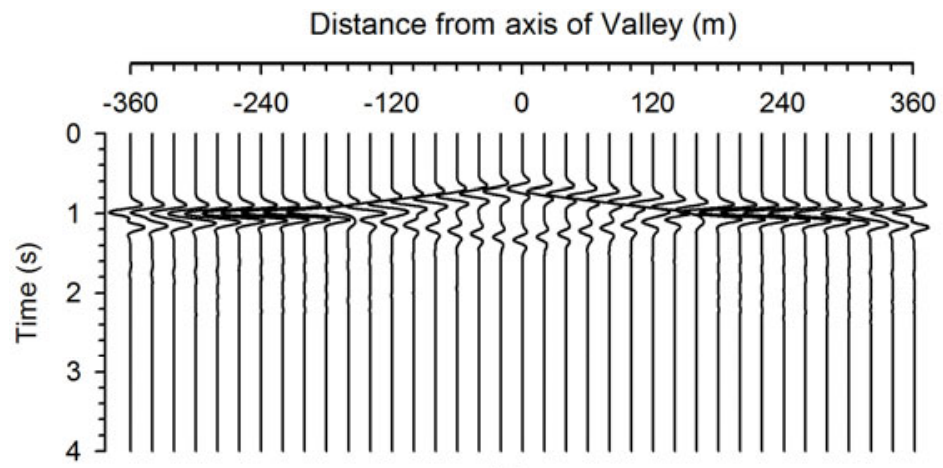

(a)

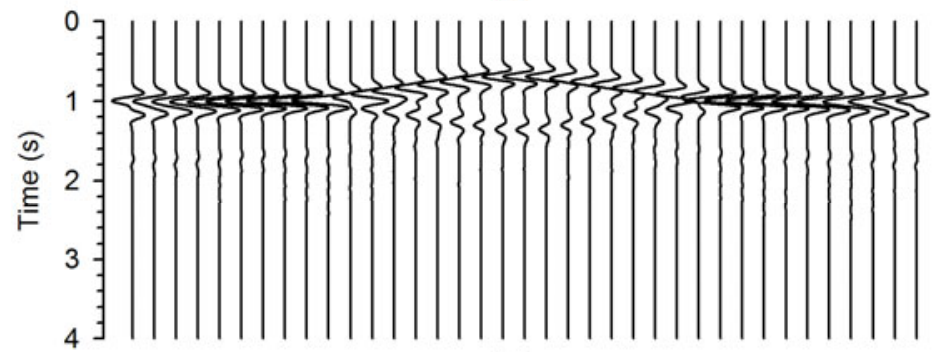

(b)

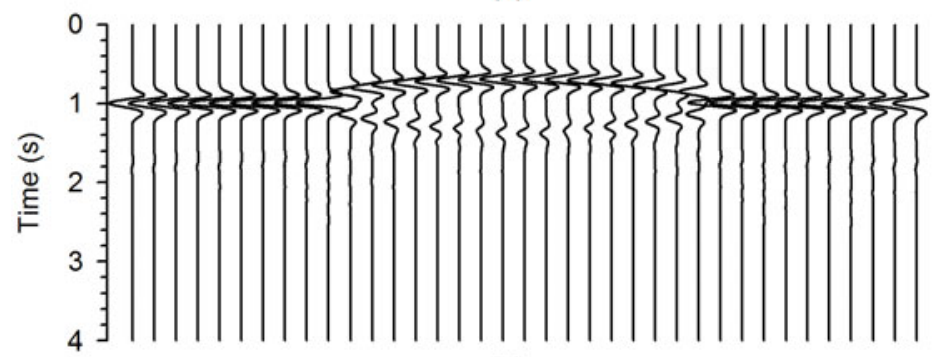

(c)

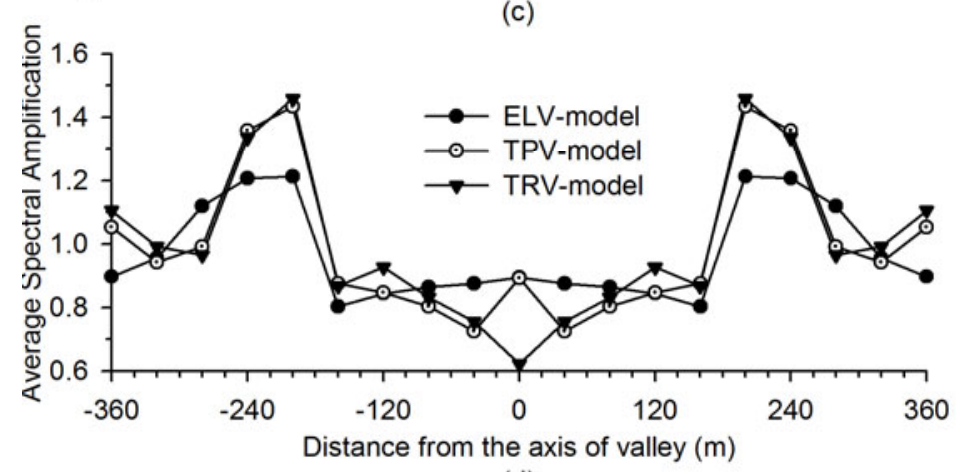

(d)

Fig. 5. $S H$-wave response of: triangular (a), trapezoidal (b), and elliptical (c) valleys; and comparison of ASA caused be considered valleys (d). 
along the flanks of the valleys. Figure $5 \mathrm{~d}$ depicts a comparison of average spectral amplification (ASA) caused by the TRV, TPV, and ELV models. The ASA at troughs of the TRV, TPV, and ELV models are 0.62, 0.9 and 0.9 , respectively. Similarly, the largest value of ASA very near the top edges (at an offset of $20 \mathrm{~m}$ ) of the TRV, TPV, and ELV models are 1.45, 1.43, and 1.21 , respectively. In case of ELV model, the ASA is larger at the trough of the valley as compared to the ASA along the slant part of the valley. Even, there is minor decrease of ASA from trough towards the top of the valley. The TRV model with a least surface area has the largest amplification at the top-edges and least amplification at the trough. It is also inferred that for an equal shape-ratio, the valley de-amplification pattern along the synclinal part is very much dependent on the shape of the valley. It may be concluded that for an equal shape-ratio, the valley de-amplification at the trough and amplification at the top-corners are larger for the valley whose surface area is less.

\section{EFFECTS OF SHAPE-RATIO OF NON-WEATHERED VALLEY}

In order to study the effects of valley shape-ratio on the ground motion characteristics, $S H$-wave responses of non-weathered triangular valley STRV1STRV4 and elliptical valley SELV1-SELV4 models with different shaperatio are computed. Both triangular and elliptical valleys have a fixed depth of $350 \mathrm{~m}$ and varying widths as $234,180,140$, and $116 \mathrm{~m}$, respectively. So, valley-shape-ratios for the STRV1-STRV4 or SELV1-SELV4 models are $1.49,1.94,2.50$, and 3.02, respectively. The $S H$-wave responses of the nonweathered STRV1-STRV4 models (left panel) and SELV1-SELV4 models (right panel) are shown in Fig. 6. An increase of valley de-focusing at the trough and diffractions from the top-edges of the valleys can be inferred with an increase of shape-ratio. The amplitude of diffracted $S H$ waves is less in the SELV models as compared to the respective STRV models.

\subsection{Spatial variation of ASA for the non-weathered valley}

Figure $7 \mathrm{a}, \mathrm{b}$ shows a comparison of spatial variation of ASA with the shaperatio for the non-weathered triangular and elliptical valleys, respectively. An analysis of this figure very clearly reveals a decrease of ASA (increase of deamplification) with an increase of shape-ratio in both the valley models for the considered models parameters and the frequency range. The ASA is least at the trough and largest at the top-corners of both the valley models. Furthermore, the obtained largest amplification near the top-corners of both the valley models is increasing with decrease of shape ratio. However, the ASA in the synclinal part of the elliptical valley is more or less same everywhere in contrast to the triangular valleys, where there is an increase of amplifica- 

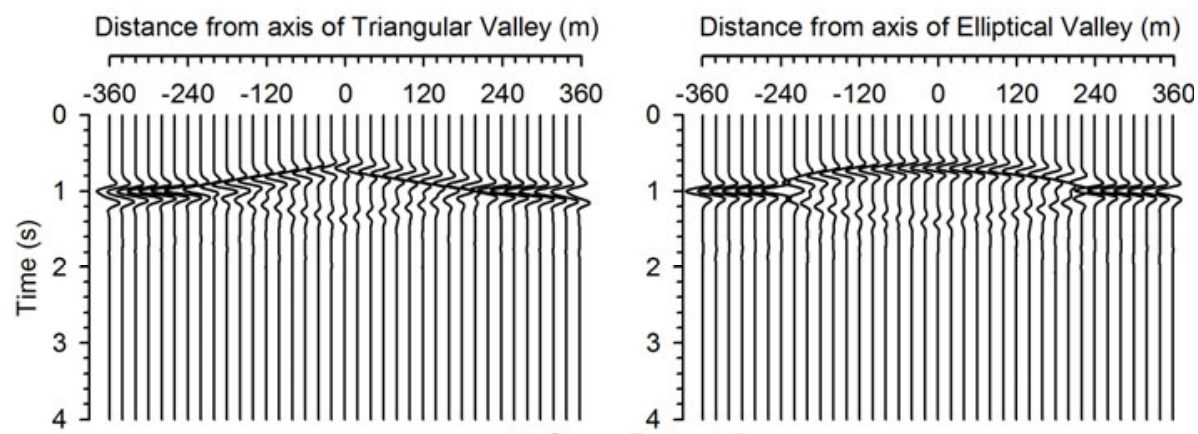

(a) Shape Ratio $=1.5$
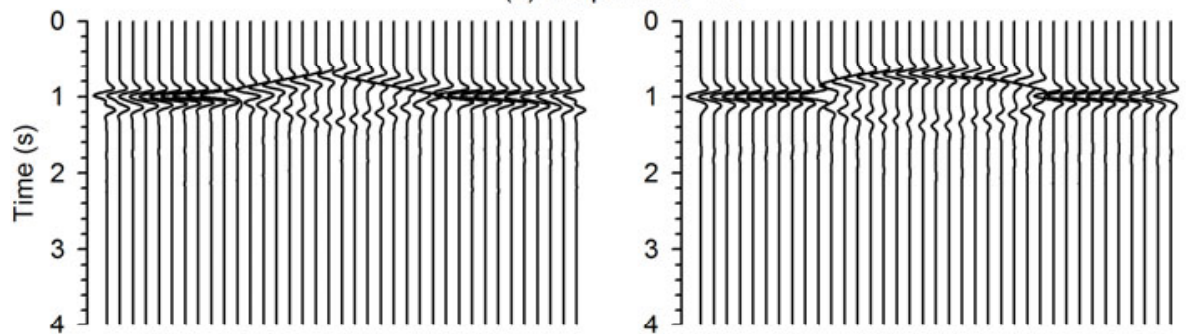

(b) Shape Ratio $=2.0$
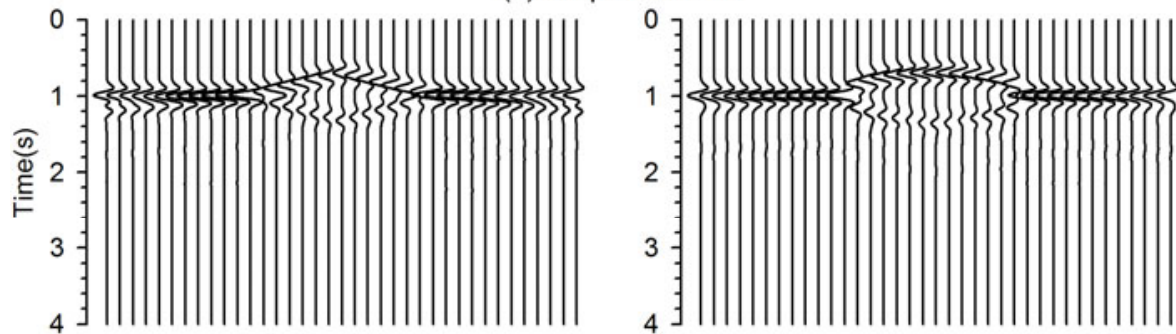

(c) Shape Ratio $=2.5$
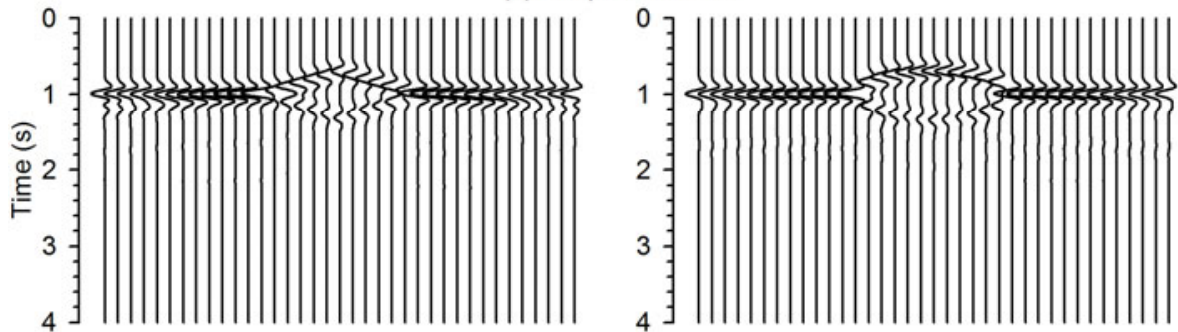

(d) Shape Ratio $=3.0$

Fig. 6. $S H$-wave response of triangular and elliptical valleys with different shape ratio.

tion towards the top-corners. Finally, it can be concluded that the de-amplification at the trough and amplification at the top-corners of the STRV models are larger than that caused by the SELV models. 


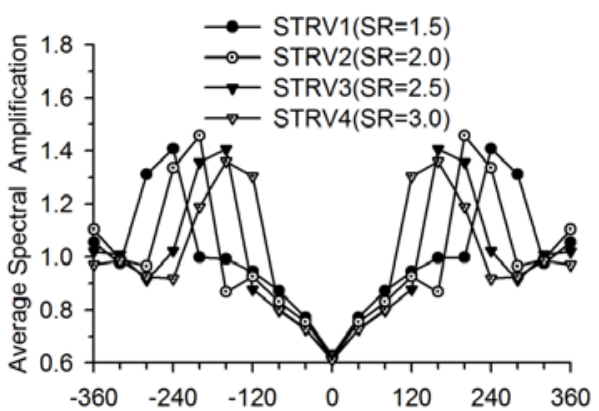

(a)

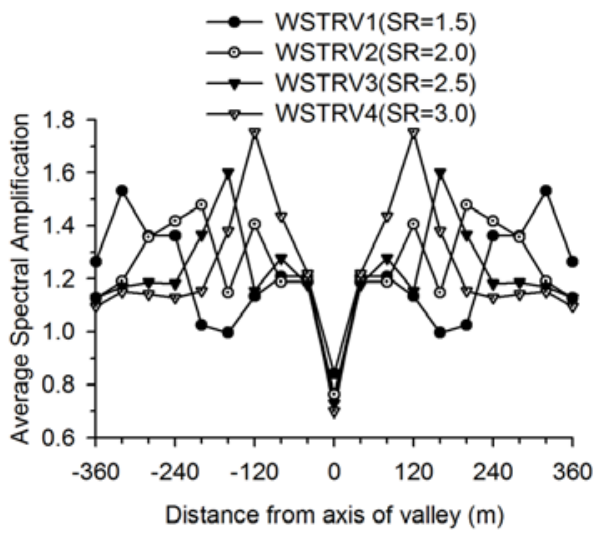

(c)

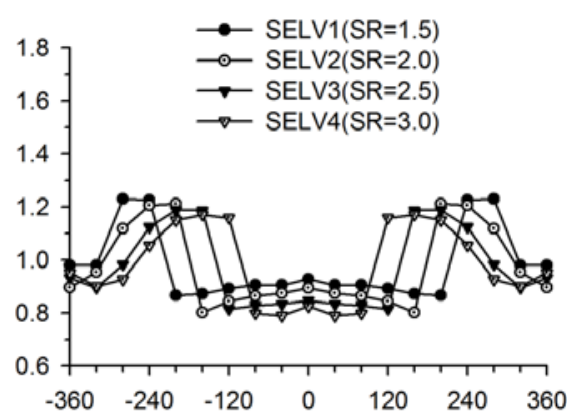

(b)

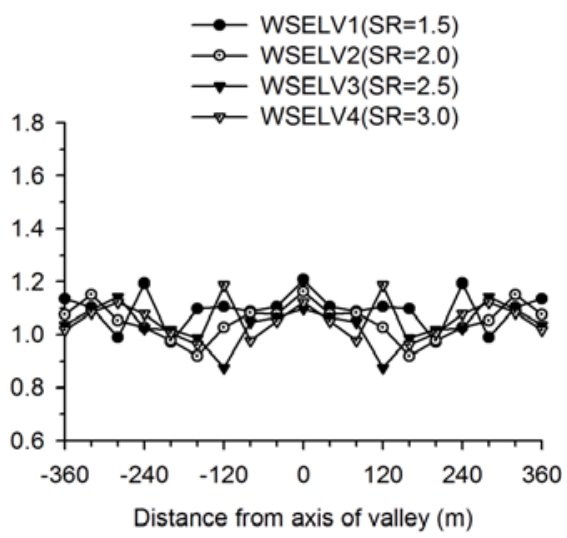

(d)

Fig. 7. Spatial variation of average spectral amplification of: STRV (a), SELV (b), WSTRV (c), and WSELV (d) models.

\subsection{Spatial variation of DGM for the non-weathered valley}

To quantify the effects of the shape-ratio on the DGM developed by the $S H$ wave along the non-weathered flanks of the STRV and SELV models, responses were computed on another array with 29 equidistant $(10 \mathrm{~m}$ apart horizontally) receiver points extending from 0 to $280 \mathrm{~m}$ leftwards of the valley-axis. Figure 8 shows the STRV model with the positions of source and receiver array. Further, before computing the DGM, all the traces were normalized with the maximum amplitude in the response of a model with no valley in the model, so that the computed DGM corresponds to the DGM caused by unit amplitude of the incident $S H$ wave. The distances between two consecutive receiver points along the valley-flanks were computed considering the shapes of the various considered valley-models. Figure 9a-d shows the computed DGM for the STRV1-STRV4 models (left panel) and SELV1-SELV4 models (right panel), respectively. Near the edges of the val- 


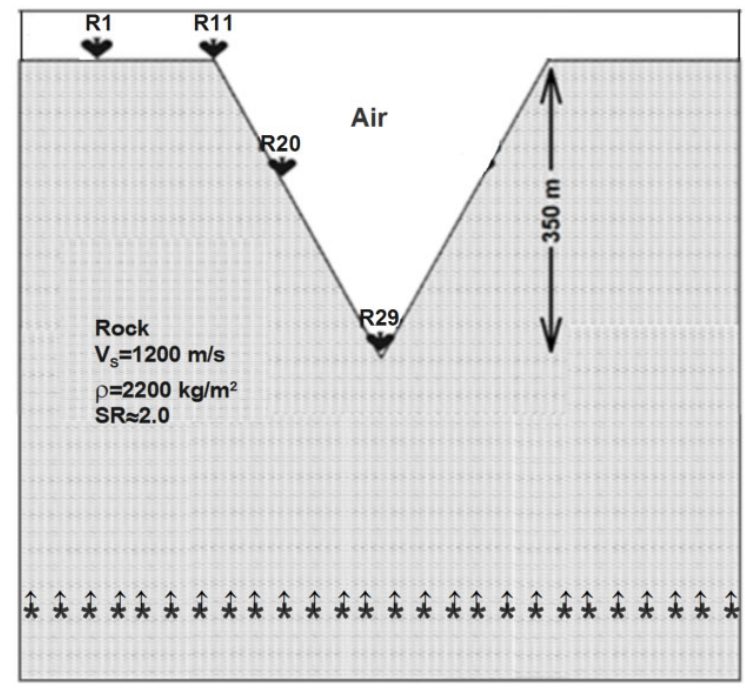

Fig. 8. Triangular valley model with the position of point sources to generate a plane wave front, air above the free surface, and a new array with 29 equidistant $(10 \mathrm{~m}$ apart) receiver points.

leys there is sudden increase and decrease of DGM. Further, DGM can also be inferred even on the horizontal flanks of the valleys caused by the diffracted waves. Figure 10a,b depicts the spatial variation of the peak DGM developed by the $S H$ wave along the flanks of the non-weathered triangular and elliptical valleys. The peak DGM at the trough of the triangular STRV1STRV4 valley models are of the order of $9.87 \times 10^{-5}, 1.11 \times 10^{-4}, 1.13 \times 10^{-4}$, and $1.08 \times 10^{-4}$, respectively for $1.0 \mathrm{~cm}$ amplitude in the incident $S H$ wave. Similarly, the peak DGM at the trough of the elliptical SELV1-SELV4 valley models is of the order of $1.88 \times 10^{-5}, 2.44 \times 10^{-5}, 4.0 \times 10^{-5}$, and $4.0 \times 10^{-5}$, respectively. Further, the largest DGMs caused by the triangular STRV1-STRV4 valleys are of the order of $2.92 \times 10^{-4}, 2.89 \times 10^{-4}, 2.58 \times 10^{-4}$, and $2.56 \times 10^{-4}$, respectively, very near to the top of the valleys. Similarly, the largest DGMs caused by the elliptical SELV1-SELV4 valleys are of the order of $2.29 \times 10^{-4}, 1.82 \times 10^{-4}, 1.8 \times 10^{-4}$, and $1.48 \times 10^{-4}$, respectively, very near to the top of the valley. Analysis of Fig. 10a, b depicts that the DGM is increasing with shape-ratio at the trough and decreasing with shape-ratio at the top-corners of the considered valleys of both types. There may be three possible reasons behind the sudden increase and decrease of DGM very near the edges of the valleys. The first one is the longer offset along the slant part of the valley as compared to the horizontal flanks. The second reason is the sudden increase of ground motion near the top corners of the valley (around 

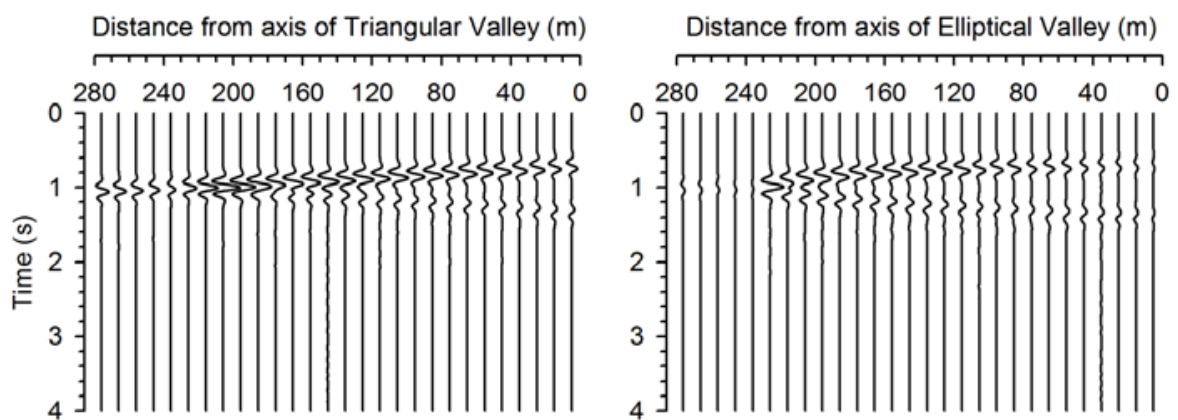

(a) Shape Ratio $=1.5$
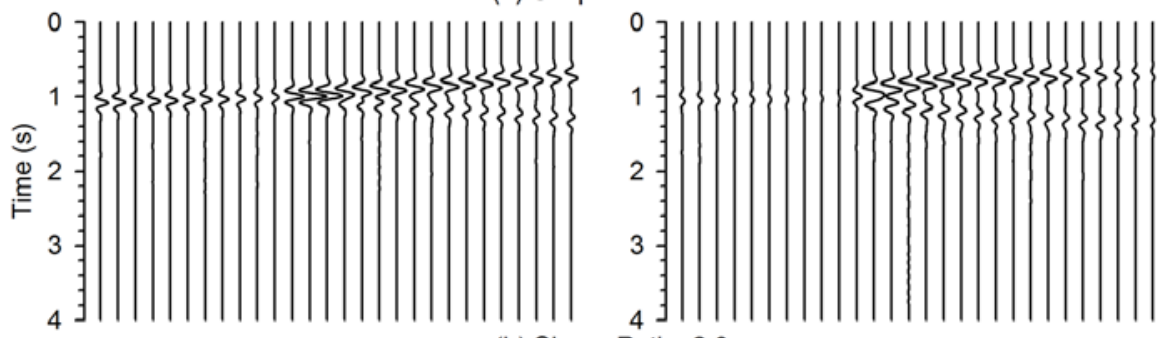

(b) Shape Ratio $=2.0$
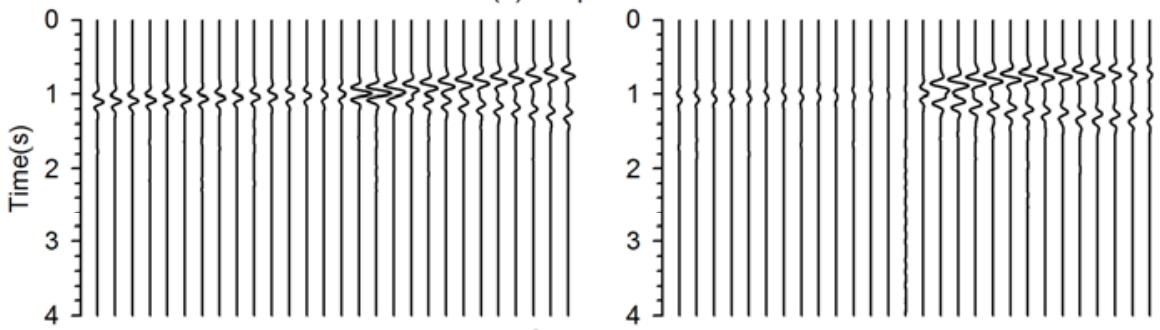

(c) Shape Ratio $=2.5$
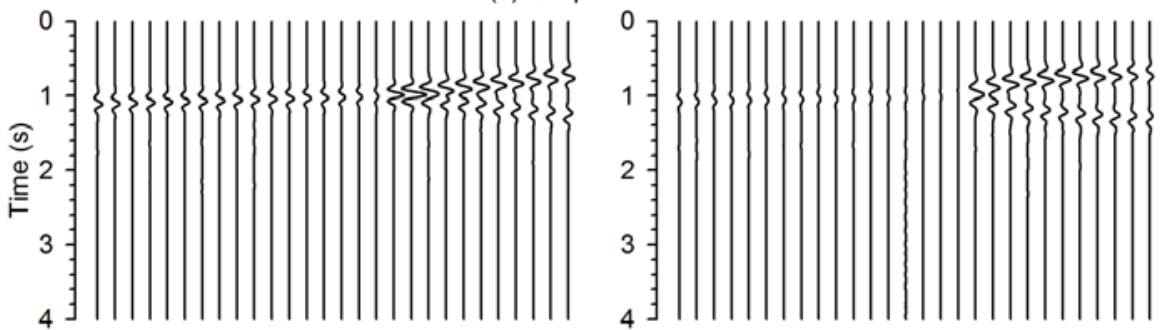

(d) Shape Ratio $=3.0$

Fig. 9. Differential ground motion (DGM) for different STRV and SELV models.

$20 \mathrm{~m}$ away from the top corners). The third reason may be the more or less simultaneous arrival of the incident plane wave front on the receiver point on the horizontal flanks and different arrival times on the slant part of the valley. Overall, the DGM developed by the triangular valleys are larger than that developed by the elliptical valleys. 


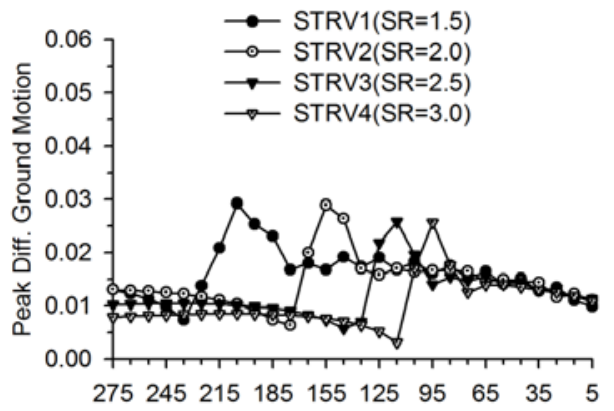

(a)

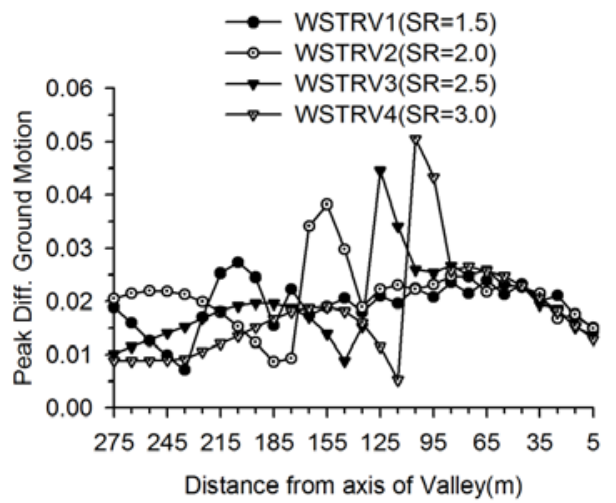

(c)

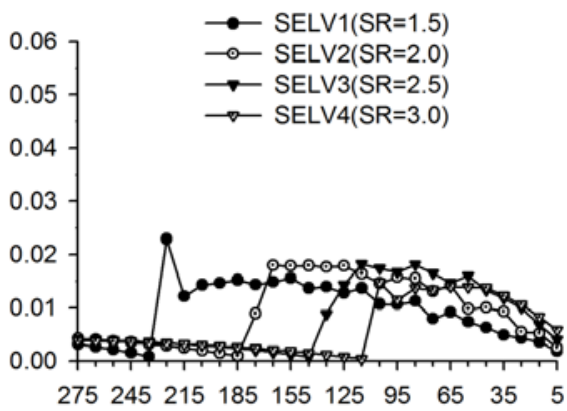

(b)

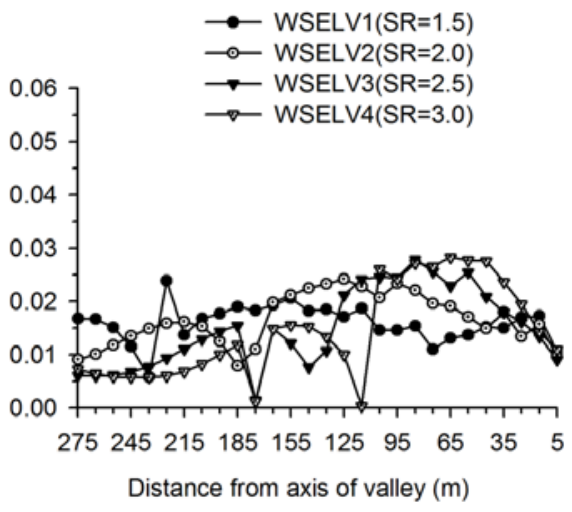

(d)

Fig. 10. Spatial variation of peak DGM for: STRV (a), SELV (b), WSTRV (c), and WSELV (d) models.

\section{EFFECTS OF THE SHAPE-RATIO OF WEATHERED VALLEY}

In order to study the combined effects of valley-weathering and the shaperatio on the ground motion characteristics, $\mathrm{SH}$-wave responses of both the triangular weathered WSTRV1-WSTRV4 models and elliptical weathered WSELV1-WSELV4 valley models were simulated. All the weathered-valley models have weathering thickness of $30 \mathrm{~m}$ on both the slant and the horizontal flanks. Further, the shape-ratios of the WSTRV and WSELV models were same as the corresponding STRV and SELV models, respectively. The $S$-wave velocity and quality factor at a reference frequency $(1.0 \mathrm{~Hz})$, density, and unrelaxed modulus of rigidity for both the viscoelastic weathering and rock are given in Table 1. In order to quantify the combined effects of shaperatio and valley-weathering, seismic responses without considering the valley but a weathering of thickness $30 \mathrm{~m}$ were also simulated. 


\subsection{Spatial variation of ASA for the weathered valley}

Figure $7 \mathrm{c}, \mathrm{d}$ shows a comparison of spatial variation of ASA with the shaperatio for the weathered triangular and elliptical valleys, respectively (please note that the amplification is computed with respect to a model containing a horizontal weathered layer over the half-space). An analysis of these figures reveals a very complex ASA pattern with shape-ratio. On an average, there is amplification of ground motion everywhere in both the weathered triangular and elliptical valleys, except at the trough of the triangular valleys. A comparison of amplification patterns of weathered and non-weathered triangular valleys depicts that the amplification on the horizontal flanks of the weathered valley is greater than the non-weathered valley. An increase of amplification with shape-ratio near the top-corners of the triangular valley can be inferred in contrast to the non-weathered triangular valleys. On the other hand, amplification levels on the horizontal flanks of the weathered and non-weathered elliptical valleys are comparable. So, it may be concluded that weathering has caused amplification of ground motion along the synclinal part of both the triangular and elliptical valleys, except at the trough of triangular valley. Further, a considerable amplification on the horizontal flanks of both valleys was obtained. In case of triangular valleys, ASA was even larger than the non-weathered triangular valleys.

\subsection{Spatial variation of DGM for the weathered valley}

Figure 11a-d shows the DGM developed by the $S H$ wave in case of the weathered WSTRV1-WSTRV4 models (left panel) and weathered WSELV1-WSELV4 models, respectively. Analysis of Fig. 10 reveals an increase of DGM with an increase of shape-ratio on the slant flanks of both the valleys. In contrast, a decrease of DGM on the horizontal flanks of both types of valleys with an increase of shape-ratio can be inferred. It appears that in case of weathered elliptical valleys trapping of waves in the weathering has developed Love waves, which is very clear in case of WSELV1 model. Figure 10c, d depicts a comparison of the spatial variation of the peak DGM for the weathered WSTRV and WSELV models, respectively. Analysis of these figures reflects an increase of peak DGM in both the WSTRV and WSELV valleys with an increase of shape-ratio and is larger than that caused by the corresponding non-weathered valley models (Fig. 10a, b). The large peaks and troughs in peak DGM near the top corners may be due to valley shape-effect. The peak DGM in case of WSELV models is comparable to that in case of WSTRV models for larger shape-ratio, but lesser in case of small shape-ratio. 

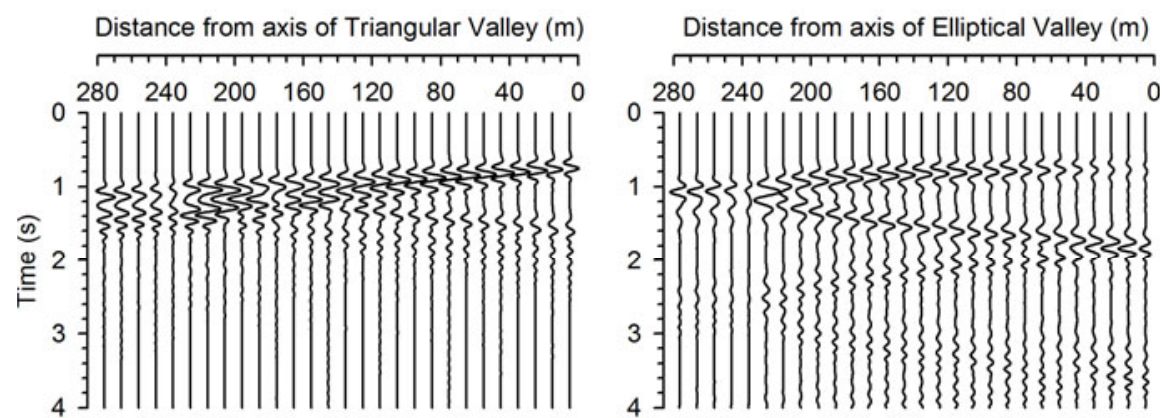

(a) Shape Ratio $=1.5$
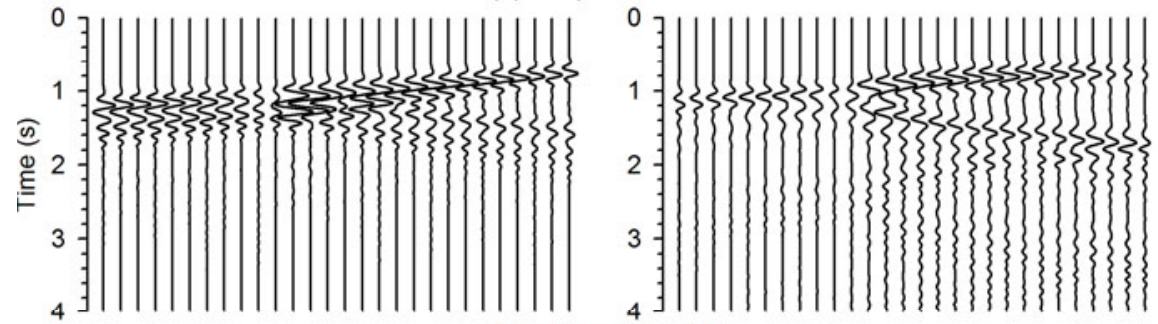

(b) Shape Ratio $=2.0$
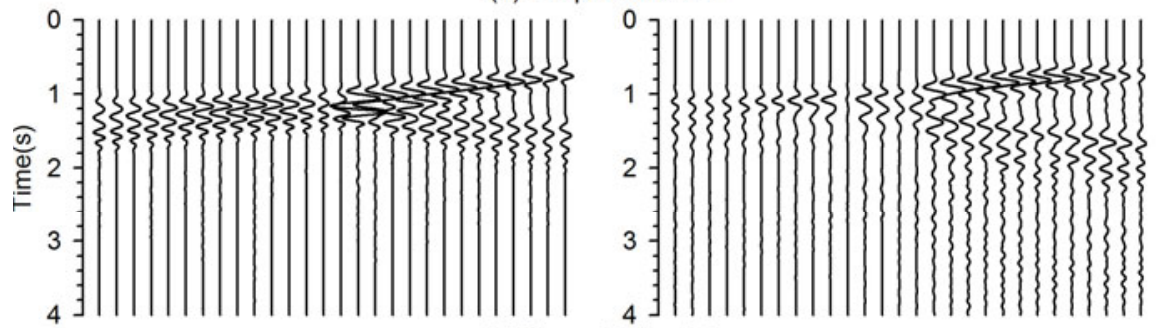

(c) Shape Ratio $=2.5$
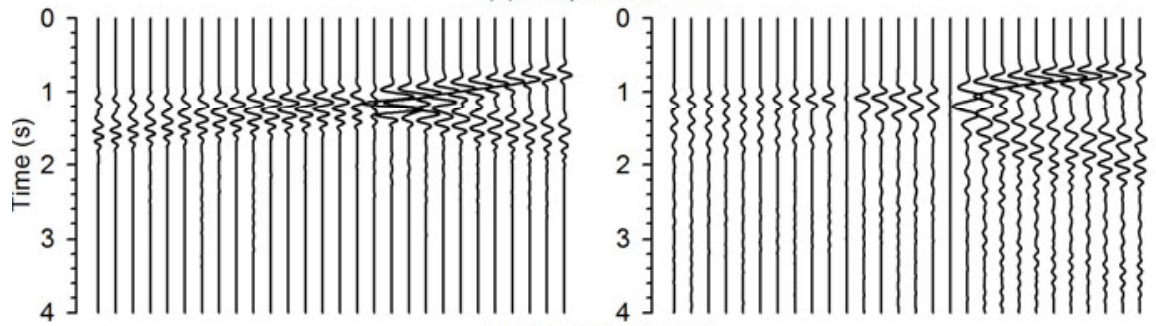

(d) Shape Ratio $=3.0$

Fig. 11. Differential Ground Motion (DGM) for different WSTRV and WSELV models with $30 \mathrm{~m}$ weathering thickness.

\section{CONCLUSIONS}

Based on the comparison of simulated result with analytical one (Faccioli 1991), it is concluded that the de-focusing caused by the valley is frequencyindependent, in contrast to the focusing caused by ridge/hill, which is fre- 
quency dependent (Geli et al. 1988). Furthermore, the valley causes amplification of all the frequencies very near its top-corners. It is also inferred that for an equal shape-ratio, the valley de-amplification at the trough and amplification at the top-corners are larger for the valley whose surface area is smaller. A decrease of the spatial variations of the average spectral amplification (ASA) for both the non-weathered triangular and elliptical valleys was obtained with an increase of the shape-ratio. There is minor decrease of ASA from trough to the top of the non-weathered elliptical valleys, in contrast to the non-weathered triangular valleys. Both de-amplification at the trough and amplification near the top-corners is larger in case of the nonweathered triangular valleys as compared to the non-weathered elliptical valleys. It may be concluded that weathering has caused amplification of ground motion along the synclinal part of both the triangular and elliptical valleys, except at the trough of triangular valley. Further, a considerable amplification on the horizontal flanks of both the valleys was obtained. In case of triangular valleys, ASA was even larger than in the non-weathered triangular valleys. A weathered triangular valley with large shape-ratio may cause unexpected damage very near its top-corners since both the ASA and DGM are the largest.

Acknowledgement. The first author is grateful to the Council of Scientific and Industrial Research, New Delhi, for the financial assistance through Grant No. CSR-569-EQD.

\section{References}

Boore, D.M. (1972), Finite difference methods for seismic wave propagation in heterogeneous materials. In: B.A. Bolt, B. Adler, S. Fernbach, and M. Rotenberg (eds.), Methods in Computational Physics, Seismology: Surface Waves and Earth Oscillations, Vol. 11, Academic Press, New York, 1-37.

Bouchon, M. (1985), A simple, complete numerical solution to the problem of diffraction of SH-waves by an irregular surface, J. Acoustic. Soc. Am. 77, 1, 15, DOI: 10.1121/1.392258.

Clayton, R., and B. Engquist (1977), Absorbing boundary conditions for acoustic and elastic wave equations, Bull. Seismol. Soc. Am. 67, 6, 1529-1540.

Emmerich, H., and M. Korn (1987), Incorporation of attenuation into time-domain computations of seismic wave fields, Geophysics 52, 9, 1252-1264, DOI: 10.1190/1.1442386.

Faccioli, E. (1991), Seismic amplification in the presence of geological and topographic irregularities. In: Proc. 2nd Int. Conf. on Recent Advances in Geo- 
technical Earthquake Engineering and Soil Dynamics, 11-15 March 1991, St. Louis, Missouri, USA, 1779-1797.

Gao, Y., N. Zhang, D. Li, H. Liu, Y. Cai, and Y. Wu (2012), Effects of topographic amplification induced by U-shaped canyon on seismic waves, Bull. Seismol. Soc. Am. 102, 4, 1748-1763, DOI: 10.1785/0120110306.

Geli, L., P.Y. Bard, and B. Jullien (1988), The effect of topography on earthquake ground motion: A review and new results, Bull. Seismol. Soc. Am. 78, 1, 42-63.

Hirai, H. (1988), Analysis of transient response of SH wave scattering in half space by the boundary element method, Eng. Anal. 5, 4, 189-194, DOI: 10.1016/ 0264-682X(88)90015-9.

Israeli, M., and S.A. Orszag (1981), Approximation of radiation boundary conditions, J. Comput. Phys. 41, 1, 115-135, DOI: 10.1016/0021-9991(81) 90082-6.

Kamalian, M., M.K. Jafari, A. Sohrabi-Bidar, A. Razmkhah, and B. Gatmiri (2006), Time-domain two-dimensional site response analysis of non-homogeneous topographic structures by a hybrid BE/FE method, Soil Dyn. Earthq. Eng. 26, 8, 753-765, DOI: 10.1016/j.soildyn.2005.12.008.

Kawase, H., and K. Aki (1990), Topography effect at the critical SV-wave incidence: Possible explanation of damage pattern by the Whittier Narrows, California, earthquake of 1 October 1987, Bull. Seismol. Soc. Am. 80, 1, $1-22$.

Kristek, J., and P. Moczo (2003), Seismic-wave propagation in viscoelastic media with material discontinuities: A 3D fourth-order staggered-grid finitedifference modeling, Bull. Seismol. Soc. Am. 93, 5, 2273-2280, DOI: $10.1785 / 0120030023$.

Kumar, S., and J.P. Narayan (2008), Absorbing boundary conditions in a fourthorder accurate SH-wave staggered grid finite difference algorithm, Acta Geophys. 56, 4, 1090-1108, DOI: 10.2478/s11600-008-0043-9.

Kumar, V., and J.P. Narayan (2013), Study of combined effects of sediment rheology and anticlinal basement topography on ground motion characteristics, Geofizika 30, 1, 75-93.

Lee, S.J., D. Komatitsch, B.S. Huang, and J. Tromp (2009), Effects of topography on seismic-wave propagation: An example from northern Taiwan, Bull. Seismol. Soc. Am. 99, 1, 314-325, DOI: 10.1785/0120080020.

Moczo, P., J. Kristek, V. Vavryčuk, R.J. Archuleta, and L. Halada (2002), 3D heterogeneous staggered-grid finite-difference modeling of seismic motion with volume harmonic and arithmetic averaging of elastic moduli and densities, Bull. Seismol. Soc. Am. 92, 8, 3042-3066, DOI: 10.1785/0120010167.

Narayan, J.P. (2003), Simulation of ridge-weathering effects on the ground motion characteristics, J. Earthq. Eng. 7, 3, 447-461, DOI: 10.1080/ 13632460309350458 . 
Narayan, J.P., and S. Kumar (2008), A fourth order accurate SH-wave staggered grid finite-difference algorithm with variable grid size and VGR-stress imaging technique, Pure Appl. Geophys. 165, 2, 271-294, DOI: 10.1007/ s00024-008-0298-8.

Narayan, J.P., and V. Kumar (2013), A fourth-order accurate finite-difference program for the simulation of SH-wave propagation in heterogeneous viscoelastic medium, Geofizika 30, 2, 173-189.

Narayan, J.P., and V. Kumar (2014), Study of combined effects of sediment rheology and basement focusing in an unbounded viscoelastic medium using P-SV-wave finite-difference modelling, Acta Geophys., DOI: 10.2478/ s11600-013-0199-9.

Narayan, J.P., and P.V. Prasad Rao (2003), Two and half dimensional simulation of ridge effects on the ground motion characteristics, Pure Appl. Geophys. 160, 8, 1557-1571, DOI: 10.1007/s00024-003-2360-X.

Narayan, J.P., and D.C. Rai (2001), An observational study of local site effects in Chamoli earthquake. In: Proc. Workshop on Recent Earthquakes of Chamoli and Bhuj, 22-23 May 2001, Roorkee, India, Indian Society of Earthquake Technology, 273-280.

Nguyen, K.V., and B. Gatmiri (2007), Evaluation of seismic ground motion induced by topographic irregularity, Soil Dyn. Earthq. Eng. 27, 2, 183-188, DOI: 10.1016/j.soildyn.2006.06.005.

Pedersen, H., B. Le Brun, D. Hatzfeld, M. Campillo, and P.Y. Bard (1994), Groundmotion amplitude across ridges, Bull. Seismol. Soc. Am. 84, 6, 1786-1800.

Sánchez-Sesma, F.J., and M. Campillo (1991), Diffraction of P, SV, and Rayleigh waves by topographic features: A boundary integral formulation, Bull. Seismol. Soc. Am. 81, 6, 2234-2253.

Sextos, A.G., A.J. Kappos, and K.D. Pitilakis (2003), Inelastic dynamic analysis of $\mathrm{RC}$ bridges accounting for spatial variability of ground motion, site effects and soil-structure interaction phenomena. Part 2: Parametric study, Earthq. Eng. Struct. Dyn. 32, 4, 629-652, DOI: 10.1002/eqe.242.

Spudich, P., M. Hellweg, and W.H.K. Lee (1996), Directional topographic site response at Tarzana observed in aftershocks of the 1994 Northridge, California, earthquake: Implications for mainshock motions, Bull. Seismol. Soc. Am. 86, 1B, 193-208.

Trifunac, M.D. (1972), Scattering of plane SH waves by a semi-cylindrical canyon, Earthq. Eng. Struct. Dyn. 1, 3, 267-281, DOI: 10.1002/eqe.4290010307.

Tsaur, D.H., and K.H. Chang (2008), An analytical approach for the scattering of $\mathrm{SH}$ waves by a symmetrical V-shaped canyon: Shallow case, Geophys. J. Int. 174, 1, 255-264, DOI: 10.1111/j.1365-246X.2008.03788.x.

Wong, H.L. (1982), Effect of surface topography on the diffraction of P, SV, and Rayleigh waves, Bull. Seismol. Soc. Am. 72, 4, 1167-1183. 
Zeng, C., J. Xia, R. Miller, and G. Tsoflias (2012), An improved vacuum formulation for 2D finite-difference modeling of Rayleigh waves including surface topography and internal discontinuities, Geophysics 77, 1, T1-T9, DOI: 10.1190/geo2011-0067.1.

Zhao, C. (2009), Dynamic and Transient Infinite Elements: Theory and Geophysical, Geotechnical and Geoenvironmental Applications, Advances in Geophysical and Environmental Mechanics and Mathematics, Springer, Dordrecht.

Zhao, C. (2010), Coupled method of finite and dynamic infinite elements for simulating wave propagation in elastic solids involving infinite domains, Sci. China Technol. Sci. 53, 6, 1678-1687, DOI: 10.1007/s11431-010-3205-3.

Zhou, G., X. Li., and X. Qi (2010), Seismic response analysis of continuous rigid frame bridge considering canyon topography effects under incident SV waves, Earthq. Sci. 23, 1, 53-61, DOI: 10.1007/s11589-009-0065-7.

Received 7 November 2013 Received in revised form 29 January 2014 Accepted 18 March 2014 